\title{
A Survey of UK Centres on Low lodine Diet Recommendations prior to Radioiodine Ablation Therapy for Differentiated Thyroid Cancer
}

\author{
Clare Yvonne England ${ }^{a, b} \quad$ Laura Moss $^{c}$ Matthew Beasley ${ }^{d}$ \\ Ingrid Haupt-Schott ${ }^{\mathrm{c}}$ Georgia Herbert ${ }^{\mathrm{a}}$ Charlotte Atkinson ${ }^{\mathrm{a}}$ \\ ${ }^{a}$ National Institute for Health Research Bristol Biomedical Research Centre, University Hospitals Bristol NHS \\ Foundation Trust and University of Bristol, Bristol, UK; ${ }^{b}$ Centre for Exercise, Nutrition and Health Sciences,

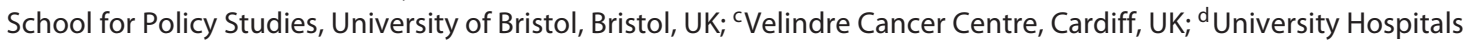 \\ Bristol NHS Trust, Bristol, UK
}

\section{Keywords}

Thyroid cancer - Low iodine diet · Radioiodine ablation · Survey

\section{Abstract \\ Background: Guidelines suggest that a low iodine diet (LID) is advised prior to radioiodine ablation (RIA) for thyroid can- cer. We aim to describe current practice regarding LID advice in the UK, determine uptake of the 2016 UK LID Working Group diet sheet and discover whether there are differences in practice. Methods: We used an online survey distributed between November 2018 and April 2019 to centres in the UK that administer ${ }^{131}$ I. We asked questions on whether a LID is advised, for how long, how advice is presented, whether and how compliance is measured and whether treatment is de- layed if LID advice is not followed. Results: Fifty-six clinicians from 47 centres that carry out RIA for thyroid cancer re- sponded. Forty-four centres (94\%) advise a LID prior to RIA, the majority for 14 days (82\%). Two-thirds of the centres use the UK LID Working Group diet sheet. Patients are told to re- sume normal eating when ${ }^{131} \mathrm{I}$ is administered at 17 centres (39\%), with 18 (41\%) advising waiting for 24-48 h after ad-}

ministration. Most centres (95\%) use only a simple question or do not assess compliance. Only $2(5 \%)$ indicate that RIA would be delayed if someone said they had not followed LID advice. Conclusions: UK practice regarding LID prior to RIA for thyroid cancer is consistent with current guidelines, but non-adherence does not usually delay RIA. The UK Low lodine Diet Working Group diet sheet is widely recognised and used. Practice could be improved by centres working to harmonise advice on when to restart a normal diet.

(c) 2019 European Thyroid Association Published by S. Karger AG, Basel

\section{Background}

Thyroid cancer accounts for less than $1 \%$ of cancer cases in the UK. However, the incidence is increasing, and between 2014 to 2016 there were an average of 3,527 new cases of thyroid cancer annually in the UK, compared to 1,125 in 1993 [1, 2]. Differentiated thyroid cancer accounts for $95 \%$ of the cases. The prognosis for differentiated thyroid cancer is good, i.e., the 10 -year survival rate is $80-90 \%$, although recurrence or persistent disease is 
estimated to occur in 10-30\% of cases [3], with rates as high as $68 \%$ observed amongst high-risk patients [4]. Treatment is often total thyroidectomy, followed by radioiodine remnant ablation with ${ }^{131}$ I (RIA) to destroy thyroid tissue remaining after surgery [5]. A high iodine status can interfere with uptake of ${ }^{131}$ I. The UK Guidelines for the management of thyroid cancer state that, based on expert opinion, exposure to iodinated contrast and treatment with drugs or supplements rich in iodine should be avoided, and people should be advised to follow a low iodine diet (LID) of 1-2 weeks prior to RIA [5]. There is, however, mixed evidence on whether LIDs impact on ablation success [6], particularly in countries with generally low iodine intakes such as the UK [7].

Two reviews have been conducted, one systematic [8] and one narrative [6], examining the use of LIDs prior to RIA. Randomised controlled trials indicate that advice to follow a LID for 1-2 weeks reduces urinary iodine. However, evidence that LID advice improves ablation success comes only from retrospective studies and is inconclusive. A study in the Netherlands [9] compared people who followed a LID for 7 days and reduced 24-h urinary iodine excretion to $<50 \mu \mathrm{g} /$ day with historic controls given no dietary advice. Those following a LID had a $65 \%$ success rate, versus $48 \%$ for the controls $(p<0.001)$. A study in South Korea [10] found only excessive iodine intake, measured as a urinary iodine-to-creatinine ratio (UI/Cr) $>250 \mu \mathrm{g} / \mathrm{g} \mathrm{Cr}$, to be associated with increased odds of unsuccessful ablation (OR: 4.74; 95\% CI: 1.78-12.63). Three other retrospective studies, in the USA [11] and South Korea [12,13], found (1) no difference in ablation success rates between cohorts that were advised a 10- to 14-day LID and historic controls who were given no advice [11]; (2) no difference between people following a very restrictive 2-week LID and those following a less restrictive 2-week LID [12]; and (3) no difference in either ablation success or spot urinary iodine concentration (UIC) between people following a 1-week and those following a 2-week LID [13].

Despite the mixed evidence, the European Association of Nuclear Medicine Therapy Committee recommends that RIA should be postponed if the UIC is $>150-200$ $\mu \mathrm{g} / \mathrm{L}[3]$ and that clinicians should aim for a UIC $<100$ $\mu \mathrm{g} / \mathrm{L}$ or a UI/Cr $<100 \mu \mathrm{g} / \mathrm{g} \mathrm{Cr}$, with optional LID advice. UK guidelines do not give details on the level of iodine restriction necessary to achieve a UI/Cr $<100 \mu \mathrm{g} / \mathrm{g} \mathrm{Cr}$, whereas American Thyroid Association guidelines advise restricting iodine intake to $<50 \mu \mathrm{g} /$ day [6]. In contrast, in South Korea, where intakes of iodine are much higher than in the UK and USA, guidelines advise restricting io- dine intake to $<100 \mu \mathrm{g} /$ day. Italian guidelines do not advise a LID at all prior to RIA [14].

In the 2000s, there were anecdotal reports in the UK that there were variations in practice and patients were finding LID advice confusing [15]. Consequently, the UK Low Iodine Diet Working Group (UK LID-WG) developed a UK LID diet sheet [16] and initially distributed it in 2016 (online suppl. documents; for all online suppl. material, see www.karger.com/doi/10.1159/000504706). It is uncertain how widespread use of the diet sheet is and, given the lack of robust evidence that a LID affects ablation success and that international guidelines differ, it is possible that practice within the UK still varies.

This study was a survey of current practice regarding advice on LIDs prior to RIA in the UK. The aims were to determine whether practice varies across different centres, whether the UK LID-WG diet sheet is in use (and if not, why not) and to discover whether centres monitor compliance with a LID and if treatment is delayed if a LID is not followed.

\section{Methods}

A short electronic survey was designed on Online Surveys (Jisc, Bristol, UK) for distribution to centres in the UK that administer ${ }^{131}$ I to people undergoing treatment for thyroid cancer. The survey included 10 main questions, with a maximum of 20 follow-ups. The questions were a mixture of multiple choice with some free text boxes and included questions on how well clinicians thought patients coped with the diet (online suppl. documents). The survey could be completed anonymously, although at the end people were asked to identify their centre. Participation in the survey was voluntary, with informed consent assumed through completion.

There is no national list of centres that administer radioiodine in the UK. A list of possible centres was created from information held by the UK LID-WG and the Internal Dosimetry Users Group and through the authors' clinical networks. A brief invitation email containing a link to the questionnaire and an explanation of the purpose of the survey was sent to identified centres in November 2018 and up to 3 reminders were sent between January 2019 and April 2019. Practice regarding who prescribes and administers RIA varies in the UK, so e-mail addresses of clinicians known personally to the authors or listed on hospital websites were used or e-mails were sent to nuclear medicine or radiology department addresses. The e-mail included the contact details on two of the authors (C.Y.E. and L.M.) so that recipients could find out more details or request no further contact. Information on and a link to the survey were also distributed at a Thyroid Cancer Study day held at the Royal Marsden Hospital, London, in December 2018. In April 2019, follow-up e-mails were sent to hospitals in regions that appeared to have low coverage.

The responses were collated and are presented descriptively. Qualitative free text responses were summarised. 
Table 1. Regional responses to the electronic survey

\begin{tabular}{lllll}
\hline Regions & $\begin{array}{l}\text { Contacted, } \\
n\end{array}$ & $\begin{array}{l}\text { RIA } \\
\text { administered, } n\end{array}$ & $\begin{array}{l}\text { RIA not } \\
\text { administered, } n\end{array}$ & $\begin{array}{l}\text { No } \\
\text { response, } n\end{array}$ \\
\hline North East England & 1 & 1 & 0 & 0 \\
North West England & 4 & 2 & 1 & 1 \\
Yorkshire and the Humber & 7 & 4 & 2 & 1 \\
East Midlands & 5 & 3 & 1 & 1 \\
West Midlands & 5 & 2 & 1 & 2 \\
East of England & 6 & 5 & 0 & 3 \\
London & 12 & 9 & 0 & 1 \\
South East England & 9 & 7 & 1 & 1 \\
South West England & 6 & 5 & 0 & 0 \\
Scotland & 4 & 4 & 0 & 0 \\
Northern Ireland & 2 & 2 & 0 & 0 \\
Wales & 3 & 3 & 0 & 11 \\
Total & 64 & 47 & 6 & 3 \\
\hline
\end{tabular}

RIA, radioiodine ablation.

\section{Results}

Sixty-four hospitals were contacted, and responses were received from 53 (83\%). Six hospitals (9\%) indicated that they were not centres using RIA for thyroid cancer. Clinicians from 47 centres administering RIA (73\%) completed the survey. For 7 centres, 2 responses were received, and for 1 centre there were 3 responses, giving a total of 56 responses. Overall, national coverage was good (Table 1). Responses were received from radiologists and nuclear medicine specialists (physicists and nurses) $(n=$ $15)$, other clinical nurse specialists $(n=12)$, clinical scientists $(n=12)$, oncologists $(n=8)$, nuclear medicine consultants $(n=3)$, unspecified consultants $(n=4), 1$ endocrinologist and 1 dietitian.

The mean estimated number of people treated with radioiodine for thyroid cancer at each centre/year was 46 (SD 28), giving a total estimated number of people treated of 2,182 annually. The minimum number treated per centre was estimated to be 10 people, the maximum 150 .

Three centres did not routinely advise a LID prior to RIA to all people. Of these, one small centre (treating approx. 10 people/year) indicated that they were not aware of the guidelines and another (treating approx. 80 people/ year) indicated that there was no evidence for effectiveness. The remaining centre (treating approx. 40 people/ year) responded that the provision of LID advice varied by clinician and it was more common not to advise the diet. Another centre also indicated that advice to follow a LID varied by clinician, and 1 centre advised a LID for only 2 days prior to RIA, whereas all others advised restriction for 1-2 weeks, as per the guidelines.

Table 2 summarises the survey answers from the 44 centres who indicated that they advised people to follow a LID. For some questionnaire items, different responses were provided by different clinicians from the same centre, as indicated in the table.

Most centres (66\%) reported using the UK LID-WG diet sheet. Of those who did not, 4 (9\%) were not aware of the working group suggestions and clinicians from 4 centres (9\%) thought it was too restrictive; one of them specifically said they did not advise people to restrict dairy products as much.

People were instructed to resume a normal diet immediately after taking ${ }^{131} \mathrm{I}$ at 17 centres (39\%), $2 \mathrm{~h}$ after taking the RIA capsule by 1 centre and $24-48 \mathrm{~h}$ after taking the capsule at 18 centres (41\%). Six centres indicated that people were instructed to resume a normal diet 24-48 h after treatment, but a LID inpatient menu was not provided. Compliance with the LID advice was assessed in 26 centres (59\%), although all except one used a simple verbal check rather than a formal dietary assessment. None of the centres reported measuring the iodine status, and only 2 clinicians said their centre would delay treatment if someone said they had not followed a LID.

Thirty-one of the 56 clinicians (53\%) indicated that they thought people coped very well with the diet, although the free text comments indicated that some groups of people were more likely to find the diet difficult - specifically, people with diabetes, vegans/vegetarians, older 
Table 2. Summary of the survey answers from 44 centres $^{1}$ advising a low iodine diet prior to radioiodine ablation

\begin{tabular}{|c|c|}
\hline & Centres, $n$ ( $\%$ of total) \\
\hline $\begin{array}{l}\text { 1. Length of LID advised } \\
2 \text { days } \\
7 \text { days } \\
10 \text { days } \\
7-14 \text { days } \\
14 \text { days }\end{array}$ & $\begin{aligned} & 1(2) \\
5 & (11) \\
1 & (2) \\
1 & (2) \\
36 & (82)\end{aligned}$ \\
\hline $\begin{array}{l}\text { 2. How LID advice is presented } \\
\text { UK LID Working Group diet sheet } \\
\text { In-house diet sheet } \\
\text { Not sure } \\
\text { UK LID Working Group diet sheet/in-house diet sheet }{ }^{2}\end{array}$ & $\begin{aligned} 29 & (66) \\
8 & (18) \\
6 & (13) \\
1 & (5)\end{aligned}$ \\
\hline $\begin{array}{l}\text { 2a. Reasons for using an in-house sheet ( } n=9 \text { centres) } \\
\text { Not aware of the working group suggestions } \\
\text { Disagree with some information } \\
\text { Own diet sheets not very different } \\
\text { Disagree with some information/own diet sheets not very different }{ }^{2}\end{array}$ & $\begin{array}{l}4(9) \\
3(7) \\
1(2) \\
1(2)\end{array}$ \\
\hline $\begin{array}{l}\text { 3. Resumption of normal diet } \\
\text { Day of admission when }{ }^{131} \mathrm{I} \text { is administered } \\
2 \mathrm{~h} \text { after }{ }^{131} \mathrm{I} \text { is administered } \\
24-48 \mathrm{~h} \text { after }{ }^{131} \mathrm{I} \text { is administered } \\
\text { After whole-body scan after ablation } \\
\text { Day of admission/24- } 48 \mathrm{~h} \text { after }{ }^{131} \mathrm{I} \text { is administered }{ }^{2} \\
\text { Fish/seafood restriction for } 24 \mathrm{~h} \text { after/after whole-body scan }{ }^{2} \\
24-48 \mathrm{~h} \text { after }{ }^{131} \mathrm{I} \text { is administered/after whole-body scan }{ }^{2} \\
\text { Not sure }\end{array}$ & $\begin{array}{c}17(39) \\
1(2) \\
18(41) \\
3(7) \\
1(2) \\
1(2) \\
2(5) \\
1(2)\end{array}$ \\
\hline $\begin{array}{l}\text { 4. A low iodine diet menu is provided for inpatients } \\
\text { Yes } \\
\text { No } \\
\text { Not sure } \\
\text { Yes } / \mathrm{no}^{2}\end{array}$ & $\begin{aligned} 17 & (39) \\
20 & (45) \\
5 & (11) \\
2 & (5)\end{aligned}$ \\
\hline $\begin{array}{l}\text { 5. Assessment of compliance with LID advice } \\
\text { Yes } \\
\text { No } \\
\text { Not sure } \\
\text { Yes/no }{ }^{2}\end{array}$ & $\begin{array}{c}22(50) \\
17(39) \\
1(2) \\
4(9)\end{array}$ \\
\hline $\begin{array}{l}\text { 5a. Methods for assessing compliance ( } n=26 \text { centres) } \\
\text { Diet assessment } \\
\text { No formal assessment, patients are verbally asked if they followed advice }\end{array}$ & $\begin{array}{c}1(2) \\
25(57)\end{array}$ \\
\hline $\begin{array}{l}\text { 5b. Delay of treatment if LID is not followed ( } n=26 \text { centres) } \\
\text { Yes } \\
\text { No } \\
\text { Not sure } \\
\text { Left blank }\end{array}$ & $\begin{aligned} & 2(5) \\
16 & (36) \\
5 & (11) \\
& 3(7)\end{aligned}$ \\
\hline $\begin{array}{l}\text { 6. Assessment of how well patients cope with the diet } \\
\text { Very well } \\
\text { Somewhat well } \\
\text { Not very well at all } \\
\text { Very well/somewhat well }^{2} \\
\text { Not very well at all/somewhat well }{ }^{2}\end{array}$ & $\begin{aligned} 21 & (48) \\
17 & (39) \\
1 & (2) \\
4 & (9) \\
1 & (2)\end{aligned}$ \\
\hline
\end{tabular}

LID, low iodine diet. ${ }^{1}$ Forty-seven centres responded to the survey, 2 indicated that the LID was not advised and 2 that it depended on the consultant ( 1 of these provided no further survey answers). ${ }^{2}$ A total of 56 clinicians responded to the survey; split responses indicate where there was disagreement between clinicians from the same centre, except for items where one of the clinicians did not know and the other gave an answer (questions 2,5b). 
people and people from non-British backgrounds. The diet was identified as being a source of anxiety for some people, and there were comments that some people were more restrictive than advised and attempted to follow noiodine diets, rather than a reduced-iodine diet. However, clinicians also said that there were people who liked feeling in control of a part of their cancer treatment, and who experienced other health benefits from thinking about what they were eating. The UK LID-WG diet sheet was highlighted as making advice clearer and easier to follow.

Two clinicians (1 clinical nurse specialist and 1 oncologist) thought that people did not cope with the diet but provided no specific comments, and 1 oncologist reported not asking about the diet because they did not think there was good evidence for its efficacy so it did not matter if people followed it or not.

\section{Discussion}

This study gives information about clinical practice regarding LIDs prior to RIA for thyroid cancer in the UK since the introduction of the UK LID-WG diet sheet [16]. The response rate was good, with very good coverage across the regions of the UK, including all the devolved nations. Most centres advise a 14-day LID, but there were variations regarding the advice given between centres. Overall, there was good awareness and usage of the UK LID-WG diet sheet and only 4 centres indicated that they were unaware of it. A further 4 centres said that they disagreed with some of the information in the sheet.

Variations in practice are perhaps unsurprising given the lack of clear evidence that following a LID or reducing the UIC improves ablation success $[6,8]$. Of the 4 centres that reported not routinely advising a LID, only 1 large centre explicitly stated that they did not think the evidence was good enough. However, adherence to the diet was either not assessed at all or assessed by a simple question by most clinicians, and only 2 indicated that treatment would be delayed if people reported that they did not follow a LID. This may reflect either a widespread lack of belief that the diet is necessary, as stated by 1 clinician, or a lack of confidence in ability to assess diet. None of the centres assessed iodine status using urinary iodine measurements, again perhaps unsurprising given concerns over inaccuracies in determining the iodine status from the UIC [17].

There appears to be most disagreement in practice about when people should restart a normal diet following RIA. Twenty-five of the 56 clinicians who answered the survey reported that they advised people to continue with dietary restriction 24-48 $\mathrm{h}$ after RIA, and 6 indicated that the LID was stopped after post-therapy whole body scanning (Px-WBS), presumably to ensure good uptake of ${ }^{131}$ I. Although we did not ask each centre to report when the Px-WBS occurred, it is carried out when residual activity permits imaging, typically around 2-10 days after RIA [5]. Studies that examined whether advice to follow a LID improves ablation success reported asking people to follow a LID prior to RIA but did not appear to ask people to continue after ${ }^{131}$ I had been administered [9-11, 13], unless a Px-WBS was carried out [12]. To our knowledge, no studies have assessed whether continuing a LID beyond the administration of RIA confers any benefit on outcomes, or what effect resuming a usual diet has on the iodine status in this immediate post-treatment period.

As a survey of practice, our study did not capture what patients think of the LID. Over half of the clinicians (53\%) indicated that people coped very well with the diet, although some suggested that there are groups of people who struggle and that some people attempt to follow a very restrictive no-iodine diet. Two studies, both conducted in South Korea, reported that people believed the LID to be important but found it difficult to follow because they enjoyed foods high in iodine, struggled to find alternatives and found it difficult to eat outside the home $[18,19]$. Difficulties with food eaten outside of the home were also reported by people in Brazil [20]. Experiences may be different in the UK, since the typical Korean diet is very high in iodine [21] and in Brazil salt is iodised [20]. However, there was anecdotal evidence that people in the UK had found LID advice confusing and difficult to follow before the UK LID-WG released the standardised diet sheet [15]. The clinicians in the current survey indicated that the standardised diet sheet has improved advice, but questions from people about the LID are still frequently posted on online forums [22]. This is perhaps because there is potential for confusion if people find online advice from countries where salt is iodised (e.g., the USA), unlike the UK.

This study is the most comprehensive overview of UK practice regarding advice on a LID prior to RIA for thyroid cancer to date, but there are some limitations. Despite good coverage, it is likely that not all UK centres have taken part. It is also possible that the clinician who completed the survey may not have been the one who knew most about practice regarding the LID in their centre, despite the initial recipient being asked to forward it to a more appropriate person if they felt they were unable to answer the questions. Overall, however, we are confident that this study is broadly representative of current 
UK practice regarding LID advice prior to RIA therapy for thyroid cancer.

We found evidence that the UK LID-WG diet sheet is recognised and used and has improved practice. Most UK practice regarding the LID is in line with current guidelines, but there are variations between centres and nonadherence to the diet does not usually delay RIA. This is, perhaps, due to lack of convincing evidence in the literature that the LID is necessary. There is a need for more research in this area, and this study is part of ongoing work investigating the LID. We are currently conducting a multicentre retrospective review of ablation success rates at UK centres giving different LID advice, a qualitative study exploring patient experiences with the LID and a mixed-method review of the literature regarding the LID prior to RIA for thyroid cancer. However, since LID advice is widely given at present, UK practice could be improved with more detailed assessment of dietary compliance as well as harmonisation of advice on when to restart a normal diet.

\section{Acknowledgements}

We would like to thank all the clinicians who completed the survey.

\section{Statement of Ethics}

Ethical approval was not required to conduct the study.

\section{Disclosure Statement}

L.M. and I.H.-S. are members of the UK Low Iodine Diet Working Group. The remaining authors report no conflict of interest.

\section{Funding Sources}

This study was funded by the NIHR Biomedical Research Centre at University Hospitals Bristol NHS Foundation Trust and the University of Bristol. The views expressed are those of the authors and not necessarily those of the NIHR or the Department of Health and Social Care.

\section{Author Contributions}

The study was conceived by all the authors. C.Y.E., G.H. and I.H.-S. drafted the survey, which was tested and refined by all the other authors. C.A., M.B., C.Y.E., I.H.-S. and L.M. researched and finalised the list of sites and disseminated the survey. C.Y.E. and C.A. analysed the results, and C.Y.E. wrote the first draft of the paper, which was commented upon by all other authors.

\section{References}

1 Smittenaar CR, Petersen KA, Stewart K, Moitt N. Cancer incidence and mortality projections in the UK until 2035. Br J Cancer. 2016 Oct;115(9):1147-55.

2 Cancer Research UK. Thyroid Cancer Incidence Statistics 2018 [Internet]. Available from: https://www.cancerresearchuk.org/ health-professional/cancer-statistics/statistics-by-cancer-type/thyroid-cancer/incidence.

3 Luster M, Clarke SE, Dietlein M, Lassmann M, Lind P, Oyen WJ, et al.; European Association of Nuclear Medicine (EANM). Guidelines for radioiodine therapy of differentiated thyroid cancer. Eur J Nucl Med Mol Imaging. 2008 Oct;35(10):1941-59.

4 Tuttle RM, Tala H, Shah J, Leboeuf R, Ghossein R, Gonen M, et al. Estimating risk of recurrence in differentiated thyroid cancer after total thyroidectomy and radioactive iodine remnant ablation: using response to therapy variables to modify the initial risk estimates predicted by the new American Thyroid Association staging system. Thyroid. 2010; 20(12):1341-9.

5 Perros P, Boelaert K, Colley S, Evans C, Evans RM, Gerrard Ba G, et al.; British Thyroid As- sociation. Guidelines for the management of thyroid cancer. Clin Endocrinol (Oxf). 2014 Jul;81 Suppl 1:1-122.

$6 \mathrm{Li} \mathrm{JH}, \mathrm{He} \mathrm{ZH}$, Bansal V, Hennessey JV. Low iodine diet in differentiated thyroid cancer: a review. Clin Endocrinol (Oxf). 2016 Jan; 84(1):3-12.

7 Miller R, Spiro A, Stanner S. Micronutrient status and intake in the UK - where might we be in 10 years' time? Nutr Bull. 2016;41(1): 14-41.

8 Sawka AM, Ibrahim-Zada I, Galacgac P, Tsang RW, Brierley JD, Ezzat S, et al. Dietary iodine restriction in preparation for radioactive iodine treatment or scanning in well-differentiated thyroid cancer: a systematic review. Thyroid. 2010 Oct;20(10):1129-38.

9 Pluijmen MJ, Eustatia-Rutten C, Goslings BM, Stokkel MP, Arias AM, Diamant M, et al. Effects of low-iodide diet on postsurgical radioiodide ablation therapy in patients with differentiated thyroid carcinoma. Clin Endocrinol (Oxf). 2003 Apr;58(4):428-35.

10 Sohn SY, Choi JY, Jang HW, Kim HJ, Jin SM, Kim SW, et al. Association between excessive urinary iodine excretion and failure of radioactive iodine thyroid ablation in patients with papillary thyroid cancer. Thyroid. 2013 Jun; 23(6):741-7.

11 Morris LF, Wilder MS, Waxman AD, Braunstein GD. Reevaluation of the impact of a stringent low-iodine diet on ablation rates in radioiodine treatment of thyroid carcinoma. Thyroid. 2001 Aug;11(8):749-55.

12 Yoo ID, Kim SH, Seo YY, Oh JK, O JH, Chung SK. The success rate of initial 131I ablation in differentiated thyroid cancer: comparison between less strict and very strict low iodine diets. Nucl Med Mol Imaging. 2012 Mar;46(1): 34-40.

13 Lee M, Lee YK, Jeon TJ, Chang HS, Kim BW, Lee YS, et al. Low iodine diet for one week is sufficient for adequate preparation of high dose radioactive iodine ablation therapy of differentiated thyroid cancer patients in iodine-rich areas. Thyroid. 2014 Aug;24(8): 1289-96.

14 Pacini F, Brianzoni E, Durante C, Elisei R, Ferdeghini M, Fugazzola L, et al. Recommendations for post-surgical thyroid ablation in differentiated thyroid cancer: a 2015 position statement of the Italian Society of Endocrinology. J Endocrinol Invest. 2016 Mar;39(3): $341-7$. 
15 Prestwich RJ, Gerrard GE. Low-iodine diet before radioiodine uptake scans or therapy flawed advice to U.K. patients. Clin Oncol (R Coll Radiol). 2005 Apr;17(2):73-4.

16 UK Low Iodine Diet Working Group. The Low Iodine Diet 2018 [Internet]. Available from: http://www.btf-thyroid.org/images/ documents/Low_Iodine_Diet_Factsheet.pdf.

17 Ji C, Lu T, Dary O, Legetic B, Campbell NR, Cappuccio FP; Sub-Group for Research and Surveillance of the PAHO-WHO Regional Expert Group for Cardiovascular Disease Prevention through Population-Wide Dietary Salt Reduction. Systematic review of studies evaluating urinary iodine concentration as a predictor of 24-hour urinary iodine excretion for estimating population iodine intake. Rev Panam Salud Publica. 2015 Jul;38(1):73-81.

18 Moon JA, Yoo CH, Kim MH, Lee SM, Oh YJ, Ryu YH, et al. Knowledge, Self-Efficacy, and Perceived Barriers on the Low-Iodine Diet among Thyroid Cancer Patients Preparing for Radioactive Iodine Therapy. Clin Nutr Res. 2012 Jul;1(1):13-22.

19 Lee KJ, Chang SO, Jung KY. Experiences with a low-iodine diet: a qualitative study of patients with thyroid cancer receiving radioactive iodine therapy. Eur J Oncol Nurs. 2016 Aug;23:43-50.

20 Padovani RP, Maciel RM, Kasamatsu TS, Freitas BC, Marone MM, Camacho CP, et al. Assessment of the Effect of Two Distinct Re- stricted Iodine Diet Durations on Urinary Iodine Levels (Collected over $24 \mathrm{~h}$ or as a Single-Spot Urinary Sample) and $\mathrm{Na}(+) / \mathrm{I}(-)$ Symporter Expression. Eur Thyroid J. 2015 Jun;4(2):99-105.

21 Kim HI, Oh HK, Park SY, Jang HW, Shin MH, Kim SW, et al. Urinary iodine concentration and thyroid hormones: Korea National Health and Nutrition Examination Survey 20132015. Eur J Nutr. 2019 Feb;58(1):233-40.

22 Thyroid Cancer Group. Thyroid cancer: information and support for people affected by thyroid cancer [Internet]. MacMillan Cancer Support. 2019. Available from: https://www. macmillan.org.uk/information-and-support/ thyroid-cancer. 